\title{
Haemodynamic Actions of Clonidine in Tetraplegia - Effects at Rest and During Urinary Bladder Stimulation
}

J.S. Kooner, MB, MRCP, ${ }^{1}$ W Edge, FFARCS, ${ }^{2}$ H.L. Frankel, MB, FRCP, ${ }^{2}$ W.S. Peart, FRCP, FRS, ${ }^{1}$ C.J. Mathias, DPhil, FRCP ${ }^{1}$

${ }^{1}$ Medical Unit, St Mary's Hospital Medical School, Norfolk Place, London.

${ }^{2}$ National Spinal Injuries Unit, Stoke Mandeville Hospital, Aylesbury, England.

\section{Summary}

We studied the haemodynamic effects of clonidine $(2 \mu \mathrm{g} / \mathrm{kg} / \mathrm{iv})$ in 7 tetraplegics and 7 normal subjects. Measurements of blood pressure, stroke volume, cardiac output and digital (finger) skin blood flow were made before and after clonidine for 60 minutes. Blood pressure, stroke volume and cardiac output did not fall in tetraplegics, unlike normals. Resting digital skin blood flow was higher in tetraplegics and fell after clonidine. In normal subjects however, an increase in digital skin blood flow occurred after clonidine. The pressor and digital vasoconstrictor responses to bladder stimulation were attenuated after clonidine. The inability of clonidine to induce a fall in blood pressure, stroke volume, cardiac output and cause peripheral vasodilatation in tetraplegics is consistent with its central sympatholytic effects. Attenuation of the responses to bladder stimulation suggest an effect on spinal sympathetic neurones.

Key words: Clonidine; Haemodynamic; Tetraplegia; Bladder stimulation.

In tetraplegics, stimuli from viscera, muscle and skin induce peripheral vasoconstriction and increase blood pressure due to activation of spinal sympathetic reflexes (Mathias and Frankel, 1983). The alpha-2 adrenoceptor agonist clonidine reduces the cardiovascular manifestations of autonomic dysreflexia and has also been used in alleviating muscle spasticity (Mathias et al., 1979; Maynard, 1986). The major action of clonidine in reducing blood pressure is in the brainstem, resulting in suppression of sympathetic outflow (Kobinger and Walland, 1967) although actions on sympathetic neurones in the spinal cord or on peripheral presynaptic alpha-2 adrenoceptors cannot be excluded (Starke and Altmann, 1973). In addition, clonidine can cause an initial transient peripheral vasoconstriction by stimulating postsynaptic alpha adrenoceptors. To investigate further the specific haemodynamic effects of clonidine in tetraplegics, we have studied the changes in blood pressure, heart rate, stroke volume, cardiac output and digital skin blood flow in response to clonidine and its effects on the cardiovascular disturbances after bladder stimulation. 


\section{Subjects and methods}

We investigated 7 tetraplegics (aged 18-37 years) with chronic and physiologically complete cervical spinal cord transection (levels C3-C7) and 7 normal subjects (aged 27-54 years) as controls. All were investigated while supine and off medication. Non-invasive measurements of blood pressure and heart rate were made using an automated sphygmomanometer (Sentron). Stroke distance (a measure of stroke volume) and cardiac index (stroke distance $\times$ heart rate, a measure of cardiac output) were calculated from measurements of peak velocity of ascending aortic blood flow, measured by continuous wave doppler ultrasound (Exerdop, Quinton Instrument Co.), stroke distance being the integral of the peak velocity profile. Digital (index finger) skin blood flow was recorded continuously using laser doppler flowmetry (Periflux PF2B). This instrument detects the doppler shift, and produces a voltage signal directly proportional to the quantity of blood flow in the microvasculature of the superficial skin (Nisson et al., 1980). Vascular resistance was calculated by dividing mean blood pressure with digital skin flow.

Digital skin temperature was measured with thermistors (Panlab). Clonidine $(2 \mu \mathrm{g} / \mathrm{kg})$ was administered over 10 minutes intravenously with an infusion pump. Bladder percussion was performed, before and after Clonidine, by firmly tapping the anterior abdominal wall close to the pubic crest for 3 minutes.

\section{Results}

After clonidine, both systolic and diastolic blood pressure fell in normal subjects $(126 \pm 4 / 74 \pm 3 \mathrm{mmHg}$ (mean $91 \pm 4)$ to $104 \pm 3 / 59 \pm 3 \mathrm{mmHg}(75 \pm 2)$, $p<0.01)$. Resting blood pressure was lower in tetraplegics $(109 \pm 5 / 65 \pm 4$ mmHg (mean $80 \pm 4$ ), $p<0.05$ ) and did not fall significantly after clonidine, $(105 \pm 5 / 58 \pm 2$ (mean $75 \pm 3)$, NS). The fall in heart rate was smaller in normals $(69 \pm 3$ to $65 \pm 5$ beats $/ \mathrm{min}, \mathrm{NS})$ as compared to tetraplegics $(68 \pm 5$ to $61 \pm 4$ beats/min, NS). In normals, mean stroke volume fell $(9.6 \pm 1 \cdot 0$ to $8.8 \pm 1.2 \mathrm{~cm}, \mathrm{NS})$, along with cardiac output $(670 \pm 80$ to $571 \pm 93 \mathrm{~cm} / \mathrm{min}$, NS). In tetrapelgics, neither stroke distance $(9 \cdot 2 \pm 0.6$ to $10.4 \pm 1 \cdot 1 \mathrm{~cm}, \mathrm{NS})$ nor cardiac index fell $(635 \pm 54$ to $659 \pm 82 \mathrm{~cm} / \mathrm{min}$, NS $)$. A biphasic response in digital skin blood flow occurred in normals after clonidine. After a small and transient fall, skin flow increased $(0.66 \pm 0.2$ to $1.46 \pm 0.2$ Volts, $p<0.05)$ with an increase in skin temperature $\left(27.1 \pm 0.4\right.$ to $\left.31.6 \pm 1.5{ }^{\circ} \mathrm{C}, p<0.05\right)$, and vascular resistance fell $(381 \pm 129$ to $57 \pm 6 \mathrm{mmHg} /$ Volts $(-68 \pm 9 \%)$, $p<0.02)$. In tetraplegics, the resting blood flow was higher and fell after clonidine $(1.9 \pm 0.2$ to $1.4 \pm 0.2$ volts, $p<0.05)$ (Fig.), with an increase in vascular resistance ( $42 \pm 7$ to $200 \pm 81$ after 5 minutes, and $57 \pm 6 \mathrm{mmHg} /$ Volts after 30 ; both $p<0.05)$. Resting digital skin temperature was higher in tetraplegics compared to normals and fell after clonidine $\left(34.6 \pm 0.3\right.$ to $\left.33.3 \pm 1.3{ }^{\circ} \mathrm{C}, \mathrm{NS}\right)$.

In tetraplegics, mean blood pressure increased after bladder stimulation, ( $84 \pm 3$ to $95 \pm 4 \mathrm{mmHg}, p<0.05$ ) accompanied by a fall in digital skin blood flow $(1.8 \pm 0.2$ to $0.6 \pm 0.2$ volts $p<0.01)$ and increase in vascular resistance $(50 \pm 6$ to $484 \pm 156 \mathrm{mmHg} /$ Volts, $p<0.05)$. After clonidine resting mean blood pressure was lower and increased in response to bladder stimulation $(77 \pm 4$ to $85 \pm 3 \mathrm{mmHg} p<0 \cdot 05)$, digital skin flow fell $(1 \cdot 4 \pm 0 \cdot 2$ to $0 \cdot 7 \pm 0 \cdot 2$ 


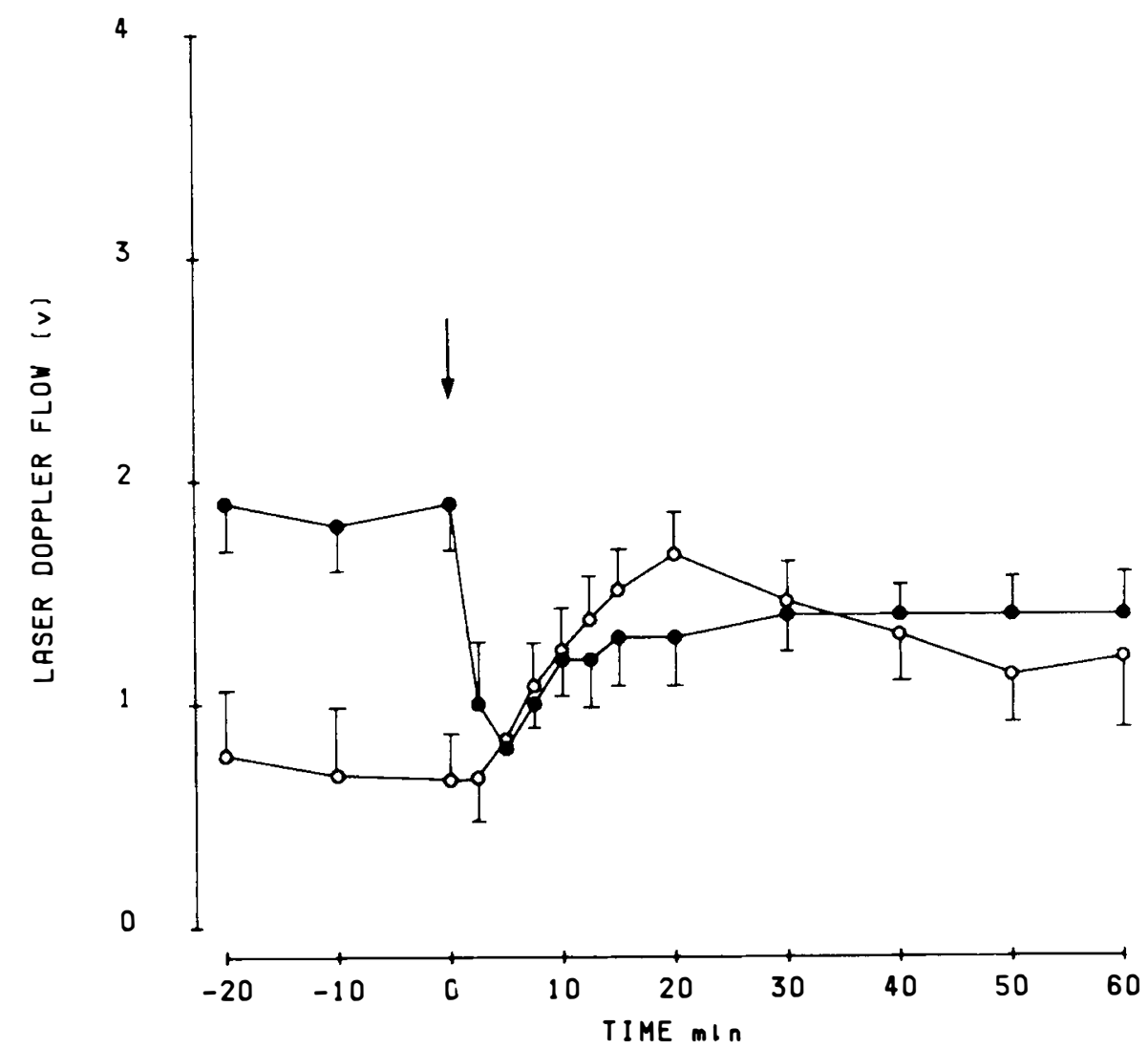

Figure Digital (index finger) skin laser doppler flow response after clonidine (arrow) in normal subjects (empty circles) and tetraplegics (filled circles). Bars indicate \pm SEM.

Volts, $p<0.01)$ and vascular resistance increased (54 \pm 5 to $315 \pm 126$ $\mathrm{mmHg} /$ Volts, $p<0.05)$. The statistical methods used were analysis of variance and $t$ tests.

\section{Discussion}

Experimental evidence indicates that clonidine lowers blood pressure by a reduction in sympathetic activity consequent upon the stimulation of central alpha-2 adrenergic receptors (Kobinger and Walland, 1967). After clonidine, we observed a fall in blood pressure in normals, but not in tetraplegics. This confirms previous findings in tetraplegics (Reid et al., 1977; Mathias et al., 1979), indicating that the hypotensive action of clonidine at rest is exerted above the level of the sypathetic outflow, probably in the brainstem.

The fall in heart rate in tetraplegics was greater than in normals. Whether this indicates a greater degree of vagal influence in such patients is unclear. The lack of fall in stroke volume and cardiac output after clonidine in tetraplegics presumably indicates that intact sympathetic pathways are necessary for this effect.

The blood flow to the hand is normally regulated by vasoconstrictor sympathetic nerves (Pickering, 1931). In this study the functional activity of these 
sympathetic vasomotor nerves was assessed by measurements of digital skin blood flow. In normal subjects clonidine caused a rise in digital skin blood flow and skin temperature with a fall in vascular resistance. In tetraplegics resting blood flow was higher, probably due to the lack of resting vasoconstrictor tone. After clonidine vasodilation did not occur; there was instead a fall in digital skin blood flow and a rise in vascular resistance. Vasoconstriction occurred in the first 5 minutes and slowly decreased, but did not fall to the previous resting level. In normal subjects this was minimal and transient. The vasoconstrictor response, which was the result of the peripheral postsynaptic alpha adrenoceptor agonist effects of clonidine, was greater in the tetraplegics; this could have resulted from a number of mechanisms which include adrenoceptor supersensitivity (Mathias et al., 1976).

In tetraplegics, bladder stimulation caused a rise in blood pressure and vasoconstriction in digital skin vessels due to increased reflex spinal sympathetic activity (Guttmann and Whitteridge, 1951; Corbett et al., 1971). The pressor and vasoconstrictor responses were smaller after clonidine suggesting inhibitory actions on spinal sympathetic preganglionic neurones. In tetraplegics the preservation, although attenuated, of the digital vasoconstrictor response after clonidine makes a peripheral presynaptic alpha adrenergic effect less likely.

Our study therefore presents further confirmation of the central sympatholytic action of clonidine in man. This includes its effects in decreasing blood pressure, causing vasodilatation in digital blood vessels and reducing stroke volume and cardiac output, which occur in normal but not tetraplegic man.

\section{Acknowledgements}

We thank P Smith for technical assistance. CJM thanks the Wellcome Trust for their support.

\section{References}

Corbett JL, Frankel HL, Harris PJ 1971 Cardiovascular reflex responses to cutaneous and visceral stimuli in spinal man. Fournal of Physiology (Lond.) 215, 395-409.

GutTMANN L, WhITTERIDGE D 1947 Effects of bladder distension on autonomic mechanisms after spinal cord injuries. Brain 70: 361-404.

KOBINGER W, WALLAND A 1967 Investigations into the mechanism of the hypotensive effect of 2(2,6-Dichlorophenylamino)-2-imidazoline-HCL. European fournal of Pharmacology 2: 155-162.

Mathias CJ, Frankel HL 1983 Autonomic failure in tetraplegia. In: Autonomic Failure: a textbook of clinical disorders of the autonomic nervous system. Ed. R Bannister, Oxford University Press, Oxford, 453-488.

Mathias CJ Frankel HL, Christensen NJ, Spalding JMK 1976 Enhanced pressor response to noradrenaline in patients with cervical spinal cord transection. Brain 99: 757-770.

Mathias CJ, Reid JL, Wing LMH, Frankel HL, Christensen NJ 1979 Antihypertensive effects of clonidine in tetraplegic subjects devoid of central sympathetic control. Clinical Science and Molecular Medicine 57: 425-428s.

MAYNARD FM 1986 Early clinical experience with clonidine in spinal spasticity. Paraplegia 24 (3): $171-182$.

Nilsson GE, Tenlan T, Oberg PA 1980 A new instrument for continuous measurement of tissue blood flow by light bearing spectroscopy. IEEC Transactions on Biomedical Engineering 27: 1-9.

PICKERING GW 1933 The vasomotor regulation of heat loss from human skin in relation to external temperature. Heart 16: 115-135.

Reid JL, Wing LMH, Mathias CJ, Frankel HL, Neill E 1977 The central hypotensive effect of clonidine: studies in tetraplegic subjects. Clinical Pharmacology and Therapeutics 21: 375381 .

STARKE GK, ALTMANN KP 1973 Inhibition of adrenergic neurotransmission by clonidine: an action of prejunctional alpha receptors. Neuropharmacology 12: 339-347. 